Article

\title{
The Influence of Housing Investment on Urban Innovation: An Empirical Analysis Based on City-Level Panel Data in China
}

\author{
Xiaojie Wang ${ }^{1}{ }^{\circledR}$, Yi Duan ${ }^{2}{ }^{\oplus}$, Pengcheng Liu ${ }^{3, *}$ and Guixin Han ${ }^{1}$ \\ 1 School of Management, Ocean University of China, Qingdao 266100, China; wangxiaojie@ouc.edu.cn (X.W.); \\ hanguixin@stu.ouc.edu.cn (G.H.) \\ 2 Department of Finance, Economics, and International Business, Marshall University, Huntington, WV 25755, \\ USA; yiduan@marshall.edu \\ 3 School of Economics, Qingdao University, Qingdao 266061, China \\ * Correspondence: qd_lpc@qdu.edu.cn; Tel.: +86-178-6663-9806
}

Received: 25 February 2020; Accepted: 30 March 2020; Published: 8 April 2020

check for updates

\begin{abstract}
The reasonable control of housing investment and the encouragement of innovation are two major tasks for the Chinese government. This article uses city-level urban panel data over 2001-2015 to study the effect of housing investment on urban innovation in China. The full-sample regression result shows that housing investment inhibits urban innovation. Housing investment can curb urban capital flow and reduce the gross profits of enterprises, which can hinder the improvement of urban innovation. As for different regions, the eastern region has been more obviously influenced by housing investment, while it has led to less influence on the middle and western regions in China. The conclusions of this study can help to clarify the internal relationship between housing investment and urban innovation, identify how to promote the current transformation and upgrading of China's real estate investment, and improve the vitality of the real economy.
\end{abstract}

Keywords: housing investment; urban innovation index; crowding out effect

\section{Introduction}

With the advancement of industrialization and urbanization, the constraint effect of factor resources on China's urban economic development has gradually caught attention. On the one hand, international competition is now becoming increasingly intense, which leads some innovative elements, such as human resources, to be scarce [1]. On the other hand, with the full use of urban land, the scarcity of land resources has intensified, resulting in land transfer prices continue to rise, which in turn has led to a continued rise in housing prices [2]. The real estate industry has become one of the hottest investment industries due to the considerable rate of return in China. In 2016, the GDP of China rose by $6.7 \%$, from which $2.4 \%$ was contributed by the real estate investment, and even if real estate investment has decreased slightly in the past two years, this contribution is still high. While the booming of real estate investment accelerates the process of urbanization $[3,4]$, it also causes a series of negative effects. Rong et al. [5] pointed out that if the productivity level could not move in line with the house prices, the price in the factor market might be distorted, and that can cause resource mismatch problems. Given a fixed amount of resources available in a city, social capital flow and resource allocation efficiency are the two major concerns for the development of urban innovation. We would like to investigate the impact of the boom of housing investment driven by constantly rising housing prices on urban innovation as it makes capital continue to flow into the housing industry. As this is a major issue directly related to urban innovation development and industrial structure upgrading, more intentional and deeper research is needed. 
Innovation-driven strategy is considered the strategic support to improve social productivity and comprehensive national strength of China. However, comparing with the active promotion in innovation development by the central government, the local governments are more enthusiastic about land lease and sales to promote housing investment than innovation promotion [6]. This is mainly because the innovation activities tend to be more slowly and riskier than housing investment [7]. The aim of profit seeking combined with the incentives of local government land policies has led to a large amount of capital inflow into the real estate industry. This investment portfolio has caused distortion on the development of regional innovation and it is of great theoretical and political significance to find the balance point of the rational development of housing investment and implement an innovation-driven development strategy.

Overall, the existing research regarding housing investment and innovation mainly focused on the following aspects. Firstly, some studies focused on the effect of housing investment on enterprise's independent innovation activities at the micro-enterprise level [8,9]. Some scholars also focused on examining the regulating effect of other variables, for example, the external impact of variables such as purchase restriction policy, financial loan term structure, and credit allocation on enterprise innovation [10-12]. However, the research carried out at the urban level is relatively rare. Lu's [13] research on the land finance and technological innovation from the urban level had some reference significance, but it was debatable to use the number of invention patents as the regional technology innovation measurement index. Although the measurement of innovation indicators in the existing research was mainly based on the number of patents, driven by the innovation catch-up strategy and patent promotion plan, China's unique government policy preference played an important role in the growth of the number of patents, resulting in a surge in the number of patents but with uneven or even lower quality, thus greatly reducing the credibility of measuring the innovation ability by the number of patents.

The second aspect was the analysis of the intrinsic influence mechanism of housing investment on innovation activities. At present, existing literature mainly focuses on theoretical explanations [8]. Some scholars focus on why there is an extrusion effect of housing investment on innovation activities. For example, Zheng et al. [14] pointed out that housing investment would promote the continuous improvement of urban infrastructure, and local governments would make more infrastructure investment and weaken the financial support for innovation [15,16]. Moreover, some scholars pointed out that there was a long-term and indirect compensation effect on the innovative activities as enterprises continued to invest in real estate, that is, enterprises could obtain higher profits through housing investment in the case of a low profit of their main business. This profit can provide strong financial support for its subsequent innovation activities [17] and the final effect depends on the magnitude of the above two opposite effects. At the regional level, the influence of the transmission mechanism of housing investment on urban innovation needs to be further clarified. Based on this, this paper will investigate the influence of housing investment on urban innovation in China and the channels of this influence.

Given this, we examine the impact of housing investment on urban innovation and its channels based on the panel data of 2001-2015 obtained by merging the data of China Urban and Industrial Innovation Report 2017 and the China Urban Statistical Yearbook. Since innovation levels among cities are different, we divide the samples into different groups, intending to provide policy implications for the implementation of the innovation-driven development strategy in China. The possible contributions of this article are as follows: Firstly, in view of the availability of data and the singularity of innovation measurement indicators, most of the existing research has analyzed the correlation between housing investment and enterprise innovation at the micro-level. This article integrates the housing investment of the city and the urban innovation of the region into a unified analytical framework, by analyzing the impact of the housing investment on urban innovation from a macro perspective. Secondly, this paper investigates the mechanism of housing investment in urban innovation and finds that housing investment tends to hinder urban innovation by suppressing the flow of capital and compressing 
the profit margin, which can help to deepen the understanding of the intrinsic relationship between housing investment and innovation.

The rest of this paper is organized as follows: the second section reviews the previous literature and puts forward the research hypothesis; the third section establishes the measurement model and explains the data source and variables; the fourth section reports and analyzes the empirical results; and the final section summarizes the research conclusions and discusses policy recommendations.

\section{Theoretical Analysis and Hypothesis}

\subsection{Analysis of the Impact of Housing Investment on Urban Innovation}

In the research on housing investment and innovation activities, many scholars agree that housing investment has a significant crowding-out effect on urban innovation. The impact of housing investment on innovation activities is mainly attributed to the reallocation of limited resources caused by housing investment [13]. Based on the endogenous growth model, large amounts of capital invested in high-margin real estate industries will squeeze savings out of the productive real economy sector, which will have a negative impact on productive investment and thus inhibit corporate innovation development of activities. [8,18]

Furthermore, the resource allocation and institutional environment of the provinces are quite different, resulting in significant heterogeneity in the innovation degree of each province. In this context, the impact of housing investment on urban innovation may vary depending on the province's regional innovation level, i.e., there may be a "screening effect" $[5,19]$. Areas with a higher innovation level tend to have a higher demand for innovation funds, which makes the inhibition effect on urban innovation by housing investment became more prominent. For regions with a low degree of innovation, the capital used for innovation and research is relatively small, and the effect of housing investment on its innovation will be lower. This "screening effect" also needs to be empirically tested.

Besides, China's reform and opening-up from the coastal to the inland presents a sequential feature, and there is an obvious spatial imbalance in the resource allocation and factor endowments in various regions, which will also make the impact of housing investment in different regions on urban innovation show a differentiated pattern. For example, the study of Kong et al. [20] found that negative lagged effects of housing investment on economic growth in China, which are different among the three regions-the eastern region shows the most significant negative effects, while the western region shows relatively insignificant. From this, we can infer that the crowding-out effect of housing investment on urban innovation also decreases from east to west in turn. Thus, the first hypothesis is proposed:

Hypothesis 1 (H1). The impact of housing investment on urban innovation is driven by the crowding-out effect.

Hypothesis 1a (H1a). There are regional differences in this crowding-out effect, mainly reflected in the more significant inhibition effect in the areas with high innovation.

Hypothesis $\mathbf{1 b}(\mathbf{H 1 b})$. The crowding-out effect in the eastern part of China is the strongest, followed by the central region and the western region.

\subsection{Analysis of the Channels of Housing Investment Affecting Urban Innovation}

At present, existing studies focus more on the direct connection between housing investment and innovation $[8,21]$. Although a few studies have shed some light on the intrinsic conduction logic between the two and pointed out that the inhibition effect of housing investment on enterprise innovation can be attributed to the resource misallocation, inefficiency, and high cost, etc. [5,21]. However, the above transmission channels have not been empirically tested. Moreover, the current 
research focuses more on the discussion at the micro-enterprise level, and few documents examine the systematic consequences of these effects on urban industrial development at the regional level.

This paper argues that there are two internal channels for housing investment to influence urban innovation: the endogenous economic growth model emphasizes the role of endogenous technological progress in economic development [22], that is, economic development depends more on the innovation capability driven by $R \& D$ investment, while capital and profit is an important input and reinvestment factor in the innovation process [22,23]. Housing investment will crowd out capital used for innovation and reduce profit margin, which will have a negative impact on urban innovation. Therefore, this paper selected the capital flow and profit margin as two intermediate channels in the regional industrial level to deeply explore the mechanism of housing investment affecting urban innovation.

\subsubsection{The Mediating Role of Capital Flows}

The rapid growth of housing investment has greatly raised the cost of land for industrial enterprises. The International Financial Report pointed out that the land cost of China's manufacturing industry was nine times that of the United States. Expanding housing investment and soaring housing prices have led to a sharp increase in the cost of acquiring a plant or leasing a house [24]. Some industrial companies have to shift their production to the suburbs, low-cost cities, and even overseas, which has increased their costs of production and circulation. According to the existing studies, most enterprises have outstanding financing constraints on research and development investment activities [25]. Cash holding is crucial to ensure the relative stability of enterprises' innovation R\&D expenditures [26], which directly affects the smooth implementation of corporate R\&D investment plans and the improvement of corporate innovation [27]. The suppression of capital flows by housing investment is not only an issue at the corporate level but may also be reflected at the industry and regional levels. A growing body of literature indicates that housing investment crowds out innovation within the same region [21,28]. It can be seen that the expansion of housing investment has increased the costs of industrial enterprises from multiple dimensions, which makes the total amount of corporate current assets across the city decrease. Innovation activities require long-term stable internal capital investment, while there is an uncertainty in innovation output. The aim of profit-seeking combined with the incentives of local government land policies has led to a considerable proportion of capital inflow into the real estate industry, which causes distortion on the development of regional innovation $[29,30]$. Therefore, it is reasonable to speculate that housing investment reduces capital flows, resulting in the suppression of innovation investment, which in turn hinders urban innovation. In order to verify the rationality of this theoretical inference, this paper proposes a second hypothesis to be tested:

Hypothesis 2 (H2). Housing investment has a restraining effect on urban innovation by reducing the capital flows of industrial enterprises.

\subsubsection{Mediating Role of Total Profit}

Another channel for housing investment to influence urban innovation is through affecting the total profit of urban enterprises. If there are high-profit investment projects with low entry barriers, many industries will deviate from their main business and allocate more resources to the high-profit assets in pursuit of short-term profit, which will lead to a simplistic social investment structure [5]. Consequently, long-term internal capital is inadequate for engaging in innovative activities [31]. According to data from the China Statistical Yearbook in 2016, the average net profit of the real estate industry exceeds $30 \%$, while that of the manufacturing industry is only about $7 \%$. When the return on housing investment is higher than the profit margin of the core business of the enterprise, the profit-seeking nature of the enterprise causes its funds to be "disconnected from the industrial entity" [32]. The excessive growth of housing investment will further lead to resource mismatch and inefficiency, and even the "low-end locking" effect, resulting in a decline in the productivity of 
industrial enterprises $[17,33,34]$ and reducing the total profit of urban enterprises in the long run [35]. The theoretical mechanism analysis in Miao and Wang (2014) indicated that enterprises allocate more resources to the high-profit assets at the cost of innovation in their main business. If the high-profit assets have little technology spillover, capital for innovation would be crowded out [8]. Real estate happens to be a typical sector with both high-profit and little technology spillover [21]. In addition, rising real estate investment will have a inhibition effect on innovation [36]. Attracted by the high returns on real estate investment, entrepreneurs tend to cut down the investment in management and innovation and make high profits by investing in the real estate across borders [37]. This is very unfavorable for the development of the real economy. In the long run, it will also cause the industrial enterprises throughout the city lack of innovation, which will eventually lead to a sharp drop in profit margins. Based on this, we propose the following research hypotheses:

Hypothesis 3 (H3). Housing investment has a restraining effect on urban innovation by compressing the profit margin of industrial enterprises.

\section{Methods}

\subsection{Econometric Model}

\subsubsection{The Basic Model}

We would like to test whether housing investment has an inhibitory effect on urban innovation. The Hausman test showed that $\mathrm{p}$-value $=0$, rejecting the null hypothesis of random effects, and a fixed-effect model should be selected. The F-tests showed that it is necessary to choose two-way fixed effects. Therefore, both the time fixed effect and the city fixed effect are included. The benchmark econometric regression model is set as follows:

$$
\operatorname{Innov}_{i t}=\alpha+\beta H I_{i t}+\gamma x_{i t}+\vartheta_{t}+\varphi_{i}+\mu_{i t}
$$

where the index it denotes city $i$ in year $t$, Innov $v_{i t}$ denotes the urban innovation index; $H I_{i t}$ represents the amount of housing investment; $x_{i t}$ is a set of control variables, including per capita GDP, the proportion of tertiary industry in GDP, science and technology expenditure, expenditure on education, the number of college students in ten thousand, the average salary of employees; $\vartheta_{t}$ is the time fixed effects, $\varphi_{i}$ is the city fixed effects, and $\mu_{i t}$ is the error term.

\subsubsection{Mediating Effect Model}

In order to more rigorously verify the rationality of housing investment affecting urban innovation and the mechanism, this paper draws on Iacobucci [38] to use the intermediary utility test method to effectively avoid the problem of ineffective mediation. Firstly, we establish a linear regression model as follows. For simplicity, we only show the relationship of core variables in the model. Control variables, time-fixed effects, and urban fixed effects are still included in the actual regression.

$$
\begin{gathered}
\operatorname{Innov}_{i t}=i_{1}+c H I_{i t}+e_{1} \\
M_{i t}=i_{2}+a H I_{i t}+e_{2} \\
\text { Innov }_{i t}=i_{3}+c^{\prime} H I_{i t}+b M_{i t}+e_{3}
\end{gathered}
$$

where Innov ${ }_{i t}$ represents the dependent variable, $\mathrm{HI}_{i t}$ represents the independent variable, $i_{1}-i_{3}$ denotes the constant term, and $e_{1}-e_{3}$ denotes the error term. The significance of the parameter $c$ in Equation (2) indicates the total effect of $H I_{i t}$ on Innov $i t . M_{i t}$ is the mediator variable, and Equations (3) and (4) are set to investigate whether there has been an indirect effect of $H I_{i t}$ on $I n n o v_{i t}$ through variable $M_{i t}$. 
Parameter $a$ in Equation (3) indicates the effect of independent variable $H I_{i t}$ on intermediate variable $M_{i t}$. Parameter $b$ in Equation (4) indicates the effect of the mediator variable $M_{i t}$ on the dependent variable Innov ${ }_{i t}$ after controlling the influence of the independent variable $H I_{i t}$. Parameter $c^{\prime}$ is the direct effect of independent variable $H I_{i t}$ on dependent variable Innov $v_{i t}$ after controlling the effect of mediator variable $M_{i t}$. In this mediation model, the mediation effect is equal to the indirect effect, which is equal to the coefficient product $a b$. Indirect effects have the following relationships with total and direct effects: $c=c^{\prime}+a b$. To confirm whether the significant mediation effect exists, we can test whether the null hypothesis of $\mathrm{H}_{0}: a b=0$ holds [39]. The mediation effect can be tested via a $Z$-test $Z_{\text {Mediation }}=Z_{a \cdot b} / \hat{\sigma} Z_{a b}$. We can estimate $a(b)$ and its standard error $S_{a}\left(S_{b}\right)$ from Equation (3) and Equation (4). $\hat{a}$ and $\hat{b}$ are the estimation of $a$ and $b$, respectively, and $\hat{S}_{a}$ and $\hat{S}_{b}$ are the standard errors of $\hat{a}$ and $\hat{b}$, respectively; according to the above parameters, we can calculate $Z_{a}=\hat{a} / \hat{S}_{a}, Z_{b}=\hat{b} / \hat{S}_{b}$, $Z_{a \cdot b}=Z_{a} \times Z_{b}, \hat{\sigma}_{Z_{a b}}=\sqrt{Z_{a}^{2}+Z_{b}^{2}+1}$ separately, and then get $Z_{\text {Mediation }}=Z_{a \cdot b} / \hat{\sigma}_{Z_{a b}}$.

Since $Z_{\text {Mediation }}$ is a normal distribution, we can test the significance of the mediating effect. At the 0.05 significance level, if $\left|Z_{\text {Mediation }}\right|>1.96$, the intermediate path is significant. The measurement equation includes two intermediate variables, the indpro of total industrial enterprises above the urban scale and the assets of the total capital of urban enterprises with units of 100 million yuan.

\subsection{Variable Selection and Data Sources}

\subsubsection{Dependent Variable}

In this paper, the dependent variable is urban innovation, which is used to measure the level of innovation at the city level. On the whole, the innovation ability is mostly measured by the single index of patent licensing, new product sales, and R\&D investment, etc. [10-12]. However, the Urban Innovation Index, which was published in the China Urban and Industrial Innovation Report 2017 [40] released by the Industrial Development Research Center of Fudan University, can more comprehensively and intuitively reflect the actual situation of urban innovation. The urban innovation index examines the value of invention patents on the city level rather than simply examining the number of patents to represent innovation capabilities. The innovation index of each city in this paper is derived from this report. The calculation process of the index is as follows: based on the patent data of inventions issued by the State Intellectual Property Office of China, the patent value of each enterprise is estimated based on the patent update model, and the value of patents is aggregated to the city level to obtain the city innovation index. To make the index comparable, this report normalizes the national total value of patents in 2001 to 100 and calculates the urban innovation index from 2001 to 2016. A larger value of the index indicates that the city has a higher level of innovation. Using this index can capture both the quantity and the quality of patents and can better reflect the essence of urban innovation. It can more fully reflect the degree of innovation at the city level.

\subsubsection{Independent Variables}

The independent variable in this paper is housing investment. The data are derived from the China Urban Statistical Yearbook from 2001 to 2016 released by the National Bureau of Statistics of the People's Republic of China, which is an informative annual report of the social-economic development status of Chinese cities. According to the statistical yearbook, housing investment refers to the investment by the real estate development enterprises, commercial construction enterprises, and other real estate development units in the construction of residential buildings. Activities in simple land deals are not included in real estate investment. The selected measurement variable is the completed volume of housing development investment in each city. We use the natural logarithm of the housing investment in our regressions. 


\subsubsection{Control Variables}

The control variables include educational expenditure [41], urban human capital (calculated by using the number of college students in ten thousand) [42,43], and the average salary of employees (calculated by using the total wages of employees divided by the number of employees, in ten thousand yuan) [44]. Besides, the paper also selects GDP per capita (in yuan) $[20,45]$ and the proportion of tertiary industry in GDP (\%) to control the influence of urban economic development level and the industrial structure on urban innovation. Considering the heterogeneity of innovation investment, this paper also adds the control variable of educational expenditure and science and technology expenditure in urban public financial budget expenditure (in ten thousand yuan). The channel variables are the total profit of urban industrial enterprises (indpro) and the total assets of urban enterprises (assets) [46] (both in ten thousand yuan). The above data are derived from the China City Statistical Yearbook from 2001 to 2016. The descriptive statistics for each variable in the model are shown in Table 1.

Table 1. Descriptive statistics of variables.

\begin{tabular}{|c|c|c|c|c|c|c|}
\hline Variable Name & Symbol & Obs & Mean & SD & Min & Max \\
\hline Urban innovation index & innov & 3901 & 4.8119 & 29.5868 & 0 & 849.0600 \\
\hline Housing investment & $\ln H I$ & 3901 & 12.5471 & 1.6179 & 4.3567 & 17.0147 \\
\hline Per capita GDP & $\operatorname{lngdpper}$ & 3901 & 9.8448 & 0.8727 & 4.5951 & 13.0557 \\
\hline $\begin{array}{l}\text { The tertiary industry } \\
\text { accounts for the proportion } \\
\text { of GDP }(100 \%)\end{array}$ & terpro & 3901 & 36.4422 & 8.4164 & 8.58 & 85.34 \\
\hline $\begin{array}{c}\text { Science and technology } \\
\text { expenditure }\end{array}$ & $\ln s c i e x p$ & 3901 & 8.7071 & 2.1040 & -2.0402 & 14.8726 \\
\hline Educational expenditure & lneduexp & 3901 & 11.4446 & 1.8767 & 3.6636 & 15.9622 \\
\hline $\begin{array}{l}\text { The number of college } \\
\text { students in ten thousand }\end{array}$ & $\operatorname{lnhumcap}$ & 3901 & 6.8897 & 1.0351 & 0.1508 & 11.8313 \\
\hline Average wage at city level & $\ln$ wage & 3901 & 10.0020 & 0.6366 & 2.2834 & 12.6780 \\
\hline $\begin{array}{c}\text { Total profits of industrial } \\
\text { enterprises }\end{array}$ & lnindpro & 3891 & 68.7260 & 190.9064 & -100.806 & 2685.4660 \\
\hline $\begin{array}{l}\text { Total current assets of the } \\
\text { enterprise }\end{array}$ & $\ln a s s e t s$ & 2817 & 928.7714 & 1800.9080 & 2.2947 & $21,374.4400$ \\
\hline
\end{tabular}

\subsection{Endogenous Treatment}

From the perspective of functional logic, there may be specific endogenous problems between the amount of housing investment and urban innovation. One is that the simultaneous existence (synchronization) may have endogenous problems caused by mutual causality. Generally speaking, regions with a higher level of innovation tend to have higher factor endowments and more active economic activities. The expansion effect of the enterprise and the promotion effect of household income will promote the development of housing investment. The second is the endogenous problem caused by missing variables. For example, local governments in different cities have different innovation incentive policies, which also tend to affect housing investment differently. We control for regional characteristic variables related to urban innovation to alleviate this problem. In addition, this paper uses instrumental variables to correct the estimation bias caused by endogeneity problems.

Instrumental variables need to be correlated with housing investment, but not directly correlated with urban innovation. In this paper, the first-order lagged variable of housing investment is used as the instrumental variable to deal with the endogenous problem. In theory, the housing investment in the previous period can affect the housing investment in the current period, but the urban innovation index in the current period cannot be affected by the previous housing investment once the current housing investment has already been controlled for. 


\section{Empirical Results and Discussion}

\subsection{Total Sample Regression Results}

Table 2 reports the empirical findings of housing investment affecting urban innovation. Considering that cities have significant differences in per capita GDP, educational expenditure, and the numbers of college students in ten thousand, etc. Columns (1)-(6) add control variables gradually to test the robustness of the regression results, and the results show that housing investment has a significant negative impact on urban innovation. With the addition of control variables item by item, the coefficient of housing investment slightly increases, which indicates that the result is robust. This result verifies hypothesis 1 , that is, on the whole, housing investment has a significant and robust inhibitory effect on urban innovation.

Table 2. Test results of housing investment affecting urban innovation.

\begin{tabular}{|c|c|c|c|c|c|c|}
\hline & (1) & (2) & (3) & (4) & (5) & (6) \\
\hline $\ln H I_{i t}$ & $\begin{array}{c}-6.7002 * * * \\
(0.8757)\end{array}$ & $\begin{array}{c}-6.6823 * * * \\
(0.8723)\end{array}$ & $\begin{array}{c}-6.7441^{* * *} \\
(0.8730)\end{array}$ & $\begin{array}{c}-6.3059^{* * *} \\
(0.8706)\end{array}$ & $\begin{array}{c}-6.2846^{* * *} \\
(0.8706)\end{array}$ & $\begin{array}{c}-6.1980 * * * \\
(0.8711)\end{array}$ \\
\hline $\operatorname{lngdpper}{ }_{i t}$ & $\begin{array}{c}-11.4638^{* * *} \\
(2.4483)\end{array}$ & $\begin{array}{c}-8.6312 * * * \\
(2.5044)\end{array}$ & $\begin{array}{c}-8.9605^{* * *} \\
(2.5134)\end{array}$ & $\begin{array}{c}-6.5580^{* * *} \\
(2.5282)\end{array}$ & $\begin{array}{c}-6.5924 * * * \\
(2.5279)\end{array}$ & $\begin{array}{c}-6.0308^{* *} \\
(2.5408)\end{array}$ \\
\hline terpro $_{i t}$ & & $\begin{array}{c}20.9016^{* * *} \\
(4.2051)\end{array}$ & $\begin{array}{c}20.6193 * * * \\
(4.2084)\end{array}$ & $\begin{array}{c}20.5955 * * * \\
(4.1826)\end{array}$ & $\begin{array}{c}20.1336^{* * *} \\
(4.1949)\end{array}$ & $\begin{array}{c}20.1567 * * * \\
(4.1926)\end{array}$ \\
\hline $\ln \operatorname{sciexp}_{i t}$ & & & $\begin{array}{c}1.0251 \\
(0.6793)\end{array}$ & $\begin{array}{l}1.6898 * * \\
(0.6837)\end{array}$ & $\begin{array}{l}1.5959 * * \\
(0.6869)\end{array}$ & $\begin{array}{c}1.5646 * * \\
(0.6866)\end{array}$ \\
\hline $\operatorname{lneduexp} p_{i t}$ & & & & $\begin{array}{c}-7.6286^{* * *} \\
(1.2376)\end{array}$ & $\begin{array}{c}-7.5934 * * * \\
(1.2376)\end{array}$ & $\begin{array}{c}-7.4530^{* * * *} \\
(1.2388)\end{array}$ \\
\hline $\operatorname{lnhumcap}_{i t}$ & & & & & $\begin{array}{c}1.7303 \\
(1.2345)\end{array}$ & $\begin{array}{c}1.6996 \\
(1.2339)\end{array}$ \\
\hline $\ln$ wage $_{i t}$ & & & & & & $\begin{array}{c}-4.2791^{* *} \\
(2.0507)\end{array}$ \\
\hline Time fixed effects & YES & YES & YES & YES & YES & YES \\
\hline City fixed effects & YES & YES & YES & YES & YES & YES \\
\hline Constant & $\begin{array}{c}234.3767^{* * *} \\
(27.0428)\end{array}$ & $\begin{array}{c}128.0338^{* * *} \\
(34.3993)\end{array}$ & $\begin{array}{c}122.7914^{* * *} \\
(34.5669)\end{array}$ & $\begin{array}{c}183.4714^{* * *} \\
(35.7381)\end{array}$ & $\begin{array}{c}173.1040^{* * *} \\
(36.4899)\end{array}$ & $\begin{array}{c}210.6336^{* * *} \\
(40.6633)\end{array}$ \\
\hline Observations & 3299 & 3299 & 3299 & 3299 & 3299 & 3299 \\
\hline R-squared & 0.0911 & 0.0985 & 0.0992 & 0.1105 & 0.1111 & 0.1124 \\
\hline Number of cities & 287 & 287 & 287 & 287 & 287 & 287 \\
\hline
\end{tabular}

Note: The value of Std. Err. in parentheses; ${ }^{* *}$, and ${ }^{* * *}$ represents the significance level of $10 \%, 5 \%$, and $1 \%$ respectively.

\subsection{Sample Regression Results of Different Levels of Innovation}

Since the allocation of resources and the institutional environment vary within and across provinces, for regions with different degrees of innovation, we would like to explore if there is any differential influence of housing investment on urban innovation and whether there is a "screening effect" due to the different levels of innovation in the provinces. All of these need to be further tested in sub-samples.

By calculating and ranking the average urban innovation index of each province from 2001 to 2015, regions with different innovation degrees of high, medium, and low are obtained, and then we divide the cities in the sample into a high group, medium group, and low group according to the urban innovation degree (We rank the innovation level from the smallest to the largest and assign the top $1 / 3$ with low innovation degree, the bottom $1 / 3$ high innovation degree, and the rest with medium innovation degree). Table 3 respectively reports the regression results of the effect of housing investment on urban innovation in areas with high, medium, and low innovation degrees. The results show that the effect of housing investment on urban innovation has a "screening effect" depending on the level of innovation. In areas with a high innovation degree, housing investment has a significant negative impact on urban innovation ability, while in areas with a medium and low innovation degree, housing investment shows a less significant negative impact on urban innovation, which indicates that 
housing investment has a greater inhibitory effect on urban innovation in cities with a higher degree of innovation. That is, the inhibitory effect of housing investment on urban innovation tends to vary, and housing investment tends to hinder the innovation of cities with high innovation degree more than cities with low degree of innovation. The resource allocation and institutional environment of each province are quite different, resulting in heterogeneity in the innovation degree of each province. In regions with a high degree of innovation, there is also a high demand for innovation capital. However, with the rapid expansion of housing investment, a large amount of capital pours into the real estate industry, which seriously reduces the capital originally used for innovation. Therefore, the higher the degree of innovation, the stronger the inhibitory effect of housing investment on urban innovation. In provinces with a low degree of innovation, the capital for innovation is relatively small, and the impact of housing investment on urban innovation will also be somewhat blunt.

Table 3. Test results of the impact of housing investment on urban innovation in regions with different innovation degrees.

\begin{tabular}{|c|c|c|c|}
\hline & (1) High-Group & (2) Medium-Group & (3) Low-Group \\
\hline $\ln H I_{i t}$ & $\begin{array}{c}-13.9002^{* * * *} \\
(2.2143)\end{array}$ & $\begin{array}{c}-0.7869 * * \\
(0.3279)\end{array}$ & $\begin{array}{c}-0.2183 * \\
(0.1190)\end{array}$ \\
\hline $\operatorname{lngdpper}{ }_{i t}$ & $\begin{array}{l}-8.2587 \\
(6.9878)\end{array}$ & $\begin{array}{l}-1.2547 \\
(0.8038)\end{array}$ & $\begin{array}{c}-1.8118^{* * * *} \\
(0.4480)\end{array}$ \\
\hline terpro $_{i t}$ & $\begin{array}{l}25.2074 * * \\
(10.8207)\end{array}$ & $\begin{array}{c}5.2659 * * * \\
(1.5219)\end{array}$ & $\begin{array}{c}0.5499 \\
(0.6099)\end{array}$ \\
\hline $\operatorname{lnsciexp}_{i t}$ & $\begin{array}{c}2.7281 \\
(1.7229)\end{array}$ & $\begin{array}{l}0.4359 * \\
(0.2346)\end{array}$ & $\begin{array}{c}0.0026 \\
(0.1107)\end{array}$ \\
\hline $\operatorname{lneduexp}_{i t}$ & $\begin{array}{c}-11.0795^{* * * *} \\
(2.7120)\end{array}$ & $\begin{array}{c}-1.8502^{* * * *} \\
(0.4773)\end{array}$ & $\begin{array}{c}-0.4809 * * \\
(0.2101)\end{array}$ \\
\hline $\operatorname{lnhumcap}_{i t}$ & $\begin{array}{c}3.1110 \\
(3.0429)\end{array}$ & $\begin{array}{c}-1.3274^{* * * *} \\
(0.4844)\end{array}$ & $\begin{array}{l}-0.2551 \\
(0.1638)\end{array}$ \\
\hline $\operatorname{lnwage}_{i t}$ & $\begin{array}{c}-14.4878 \\
(11.8754)\end{array}$ & $\begin{array}{l}-0.7821 \\
(0.6562)\end{array}$ & $\begin{array}{c}0.0340 \\
(0.2192)\end{array}$ \\
\hline Time fixed effects & YES & YES & YES \\
\hline City fixed effects & YES & YES & YES \\
\hline Constant & $\begin{array}{c}483.3346^{* * *} \\
(140.7016)\end{array}$ & $\begin{array}{c}50.2790 * * * \\
(13.7788)\end{array}$ & $\begin{array}{c}30.4207^{* * * *} \\
(6.0132)\end{array}$ \\
\hline Observations & 1350 & 1219 & 730 \\
\hline R-squared & 0.1767 & 0.2250 & 0.2732 \\
\hline Number of cities & 115 & 106 & 66 \\
\hline
\end{tabular}

\subsection{Spatial Heterogeneity Regression Results of Housing Investment on Urban Innovation}

In view of the special situation of China's economic development, there are great differences in history, culture, and natural endowments among different regions. Since the reform and opening-up were implemented in different regions sequentially (from east to west), we would like to explore if the impact of housing investment on innovation also varies based on this pattern.

In terms of R\&D activities that reflect the level of innovation, the R\&D efficiency of the eastern regions is relatively higher than in other regions. According to the 2012 China Statistical Yearbook, the Yangtze river delta region accounts for $42.1 \%$ of the country's patent licenses, while the number of patents granted in the middle and western regions is significantly less [47]. Significant regional heterogeneity characteristics also influence innovation through factors such as the scale of regional industry cluster [48], which is manifested in the geographic agglomeration and the huge difference among regions [49]. To accurately describe whether housing investment has a partial influence on urban innovation due to this geographical difference, we further analyze the relationship between the two by dividing China into eastern, middle, and western regions according to their economic 
development level and geographical location. The eastern region include Beijing, Hebei, Tianjin, Liaoning, Shanghai, Shandong, Zhejiang, Jiangsu, Guangdong, Fujian, and Hainan; the middle region includes Anhui, Shanxi, Henan, Heilongiiang, Jilin, Hunan, Hubei, and Jiangxi; and the western region includes Gansu, Shaanxi, Inner Mongolia, Ningxia, Qinghai, Xinjiang, Guizhou, Guangxi, Sichuan, Yunnan, and Chongqing (excluding Tibet since the data are limited). The regression results are shown in Table 4. Equation (1) shows that housing investment significantly reduces urban innovation in eastern China, while the results of Equation (2) and Equation (3) show that housing investment has no significant impact on urban innovation in central and western China.

Table 4. Results of the influence of housing investment on urban innovation in east and central and western regions.

\begin{tabular}{|c|c|c|c|}
\hline & (1) Eastern Regions & (2) Middle Regions & (3) Western Regions \\
\hline \multirow[t]{2}{*}{$\ln H I_{i t}$} & $-18.8427^{* * *}$ & $-0.6619 *$ & $-0.7111^{*}$ \\
\hline & $(2.6413)$ & $(0.3666)$ & $(0.4070)$ \\
\hline \multirow{2}{*}{$\operatorname{lngdpper}{ }_{i t}$} & -6.9653 & 0.9201 & -0.5354 \\
\hline & $(7.2290)$ & $(1.5217)$ & $(1.0309)$ \\
\hline \multirow[t]{2}{*}{ terpro $_{i t}$} & $28.7836^{* *}$ & -0.6974 & $4.6758^{* *}$ \\
\hline & $(13.7050)$ & $(1.9573)$ & $(1.8816)$ \\
\hline \multirow[t]{2}{*}{$\ln$ sciexp $_{i t}$} & $3.8781 *$ & $0.8241 * * *$ & 0.1347 \\
\hline & $(2.2119)$ & $(0.2902)$ & $(0.3244)$ \\
\hline \multirow[t]{2}{*}{$\ln e d u e x p_{i t}$} & $-12.2000^{* * *}$ & $-1.5756^{* * *}$ & $-1.7005^{* *}$ \\
\hline & (3.1924) & $(0.5757)$ & $(0.6609)$ \\
\hline \multirow[t]{2}{*}{$\operatorname{lnhumcap} i t$} & 2.2243 & -0.0377 & $-1.1336^{* *}$ \\
\hline & $(3.2470)$ & $(0.6072)$ & $(0.5710)$ \\
\hline \multirow[t]{2}{*}{$\ln _{\text {wage }} e_{i t}$} & -3.9742 & $-5.3254^{* * *}$ & -0.0305 \\
\hline & $(4.9795)$ & $(1.8274)$ & $(0.8276)$ \\
\hline Time fixed effects & YES & YES & YES \\
\hline City fixed effects & YES & YES & YES \\
\hline \multirow[t]{2}{*}{ Constant } & $429.7288^{* * *}$ & $77.8636^{* * *}$ & $33.8510 * *$ \\
\hline & $(113.0175)$ & $(26.6712)$ & $(16.9450)$ \\
\hline Observations & 1182 & 1169 & 948 \\
\hline R-squared & 0.1827 & 0.1660 & 0.1258 \\
\hline Number of cities & 101 & 99 & 87 \\
\hline
\end{tabular}

From the results of Table 2 to Table 4, it can be seen that the effect of housing investment on urban innovation is dominated by the crowding-out effect, which has obvious regional differences. Due to the "screening effect" of the provincial innovation degree, the crowding-out effect of housing investment on urban innovation is more obvious in provinces with higher innovation degree. From the perspective of regional distribution, the inhibiting effect of housing investment on urban innovation gradually weakens from east to west, which verifies the rationality of hypothesis 1 .

\section{Channels of Housing Investment Affecting Urban Innovation}

Then, we focus on testing the channels of housing investment inhibiting urban innovation, that is, whether housing investment inhibits urban innovation by inhibiting capital flow or compressing the profit margins.

Table 5 reports the test results of the effects of the rapid expansion of housing investment on capital flow and thus on urban innovation. The coefficient of $\ln H \mathrm{I}_{i t}$ in column (1) indicates that there is a negative effect of $H I_{i t}$ on Innov $_{i t}$. Columns (2) and (3) are set to investigate whether there is a mediation effect of $\mathrm{HI}_{i t}$ on $\mathrm{Innov}_{i t}$ through capital flow. To determine whether there exists a significant mediation effect, we estimate the coefficient of $\ln H \mathrm{I}_{i t}$ and its standard error in column (2), and the estimated coefficient of lnassets and its standard error in column (3). According to the calculation 
formula mentioned above, we can calculate the $Z_{\text {Mediation }}$ to test the significance of the mediation effect. The results indicate that the mediating effect value of capital flow between housing investment and urban innovation is $Z_{\text {mediation }}=-9.28$, whose absolute value is far greater than the critical value of 1.96. This verifies the existence and significance of the mediating path of capital flow, and thus indicates that the rapid expansion of housing investment significantly inhibits capital flow and thus hinders urban innovation. In other words, the increase in housing investment will push up the price of labor force, land, and other factors, resulting in a decrease in the total amount of working capital and innovation input, which then hinders the improvement of urban innovation. This provides evidence for hypothesis 2 .

Table 5. Effects of housing investment on urban innovation through restraining capital flow.

\begin{tabular}{|c|c|c|c|}
\hline & (1) & (2) & (3) \\
\hline & Innov & $\ln a s s e t s$ & Innov \\
\hline $\ln _{\text {assets }}{ }_{i t}$ & & & $\begin{array}{c}0.0255^{* * *} \\
(0.0006)\end{array}$ \\
\hline $\ln H I_{i t}$ & $\begin{array}{c}6.1980 * * * \\
(0.8711)\end{array}$ & $\begin{array}{c}-367.5589 * * * \\
(38.6587)\end{array}$ & $\begin{array}{c}0.0521 \\
(1.0815)\end{array}$ \\
\hline Control variables & YES & YES & YES \\
\hline Time fixed effects & YES & YES & YES \\
\hline City fixed effects & YES & YES & YES \\
\hline Constant & $\begin{array}{c}210.6336^{* * *} \\
(40.6633)\end{array}$ & $\begin{array}{c}8496.3054^{* * *} \\
(1979.6770)\end{array}$ & $\begin{array}{c}101.4660 * \\
(57.6400)\end{array}$ \\
\hline Observations & 3299 & 2500 & 2226 \\
\hline R-squared & 0.1124 & 0.3878 & 0.5547 \\
\hline Number of citycode & 287 & 287 & 287 \\
\hline
\end{tabular}

Notes: $Z_{a}=9.51, Z_{b}=-42.5, Z_{a b}=-404.08, \sigma_{\text {Zab }}=43.56, Z_{\text {mediation }}=-9.28<-1.96$. The value of Std. Err. in parentheses; ${ }^{*}$ and ${ }^{* * *}$ represents the significance level of $10 \%$ and $1 \%$ respectively.

Table 6 reports the empirical findings of the impact of housing investment on urban innovation though squeezing profit margin. The coefficient of $\ln \mathrm{HI}_{i t}$ in column (1) indicates that there is a negative effect of $\mathrm{HI}_{i t}$ on Innov $_{i t}$. Columns (2) and (3) are set to investigate whether there is an mediation effect of $H \mathrm{I}_{i t}$ on Innov $_{i t}$ through profit margin. To determine whether there exists a significant mediation effect, we extract estimate the coefficient of $\ln H I_{i t}$ and its standard error in column (2), and the estimated coefficient of lnindpro and its standard error in column (3). The regression results indicate that the mediating effect of profit margin in housing investment and urban innovation is $Z_{\text {mediation }}=6.30$, and its absolute value exceeds the critical value of 1.96 , which also verifies the mediating effect of the profit margin. That is to say, with the expansion of housing investment, the total profit of enterprises is significantly reduced, and the investment of urban innovation is sharply reduced, which ultimately has an inhibiting effect on urban innovation. This conclusion is consistent with the previous research on housing investment which suggested that real estate expansion has a crowding-out effect on the real economy [50], reduces the investment of enterprises in the core business, has a significant impact on the total profit of enterprises, reduces the investment and development of innovative products, and thus inhibits the improvement of urban innovation. This supports hypothesis 3 , that is, housing investment has an inhibiting effect on urban innovation by compressing the profit margin. 
Table 6. Effects of housing investment on urban innovation through squeezing profit margin.

\begin{tabular}{|c|c|c|c|}
\hline & (1) & (2) & (3) \\
\hline & Innov & lnindpro & Innov \\
\hline $\ln$ indpro $_{i t}$ & & & $\begin{array}{c}0.1572 * * * \\
(0.0037)\end{array}$ \\
\hline $\ln H I_{i t}$ & $\begin{array}{c}-6.1980 * * * \\
(0.8711)\end{array}$ & $\begin{array}{c}-23.4676^{* * *} \\
(3.6818)\end{array}$ & $\begin{array}{c}-2.5806^{* * *} \\
(0.6923)\end{array}$ \\
\hline Control variables & YES & YES & YES \\
\hline Time fixed effects & YES & YES & YES \\
\hline City fixed effects & YES & YES & YES \\
\hline Constant & $\begin{array}{c}210.6336^{* * *} \\
(40.6633)\end{array}$ & $\begin{array}{c}8496.3054^{* * *} \\
(1979.6770)\end{array}$ & $\begin{array}{c}101.4660 * \\
(57.6400)\end{array}$ \\
\hline Observations & 3299 & 2500 & 2226 \\
\hline R-squared & 0.1124 & 0.3878 & 0.5547 \\
\hline Number of citycode & 287 & 287 & 287 \\
\hline
\end{tabular}

\section{Conclusions}

The "de-realization of capital flow" not only poses the risk of the financial bubble but also restricts the development of the real economy, especially innovation development. Based on the panel data from 2001 to 2015 obtained from the China Urban and Industrial Innovation Report 2017 and the China City Statistical Yearbook, this article empirically tested the influence of housing investment on urban innovation. In general, the expansion of housing investment has significantly hindered the improvement of urban innovation, and, according to the sub-sample regression analysis of regions with different degrees of innovation, it was found that the higher degree of innovation, the more negative the effect of the housing investment on urban innovation. On this basis, this paper further studied the spatial heterogeneity of the impact of housing investment on urban innovation. The results show that the influence of the housing investment on urban innovation varies across regions; specifically, housing investment had more restraint on the improvement of urban innovation level in the eastern region, while the impact on the central and western regions was not significant. What is more, this paper further tested the channels of housing investment on the urban innovation, and the results show that inhibiting capital flow and compressing the profit margins were the intermediate channels for housing investment to inhibit the improvement of urban innovation. This result is of great significance for further determining the factors affecting urban innovation, and it is also very important to the current real estate transformation and upgrading as well as to the real economy in China.

While continuing to deepen the development of the real estate market, reasonably controlling the price fluctuations of the factors of production and guiding rational investment in society are important ways of increasing innovation. Considering that the impact of housing investment on urban innovation varies across regions, the regional differentiation of housing investment strategy should be implemented. The eastern region should constrain the overheating of housing investment, reduce the over-reliance on housing investment, especially the hollowing-out effect on the real economy, decrease the negative impact on the improvement of urban innovation, and guide the flow of resources to enhance urban innovation. In view of the fact that housing investment has no significant impact on urban innovation in the central and western regions, housing investment tends not to be a major problem there, especially when the funds invested in real estate in the western region are relatively small and it is necessary to develop the real estate in the western region moderately. As housing investment drives up the operating costs of industrial enterprises, policies and measures, such as wage subsidies or innovation subsidies, should be implemented to encourage industrial enterprises to increase the investment in innovative projects and enhance the competitiveness of industrial enterprises. It is of great policy significance for the reasonable control of housing investment and the improvement 
of the urban innovation level to guide the residents to take the real estate market rationally, restrain their speculative demand and real estate bubble, and improve their consumption ability for innovative products and high-tech products.

Author Contributions: X.W. designed the study protocol, drafted the manuscript. Y.D. revised the manuscript and conducted the model validation, and P.L. cleaned and analysed the data, reviewed and edited the manuscript. G.H. revised the manuscript. All authors have read and agreed to the published version of the manuscript.

Funding: This research was funded by [Social Science Planning Project of Shandong Province] grant number [17CQXJ04].

Acknowledgments: We thank the anonymous reviewers for many constructive comments that helped to improve the quality of this article.

Conflicts of Interest: The authors declare that they have no conflict of interest.

\section{References}

1. Daoud, A. Unifying studies of scarcity, abundance, and sufficiency. Ecol. Econ. 2018, 147, 208-217. [CrossRef]

2. Su, F.; Tao, R. The China model withering? Institutional roots of China's local developmentalism. Urban Stud. 2017, 54, 230-250. [CrossRef]

3. Barnett, J. The Fractured Metropolis: Improving the New City, Restoring the Old City, Reshaping the Region; Routledge: Abingdon-on-Thames, UK, 1996.

4. Scott, A.J. Land redevelopment and the built environment in third-wave cities: Review and synthesis. J. Urban Technol. 2019, 26, 57-81. [CrossRef]

5. Rong, Z.; Wang, W.; Gong, Q. Housing price appreciation, investment opportunity, and firm innovation: evidence from China. J. Hous. Econ. 2016, 33, 34-58. [CrossRef]

6. Pan, J.N.; Huang, J.T.; Chiang, T.F. Empirical study of the local government deficit, land finance and real estate markets in China. China Econ. Rev. 2015, 32, 57-67. [CrossRef]

7. Belloc, F.; Laurenza, E.; Rossi, M.A. Corporate governance effects on innovation when both agency costs and asset specificity matter. Ind. Corp. Chang. 2016, 25, 977-999. [CrossRef]

8. Miao, J.; Wang, P. Sectoral bubbles, misallocation, and endogenous growth. J. Math. Econ. 2014, 53, 153-163. [CrossRef]

9. Xie, J.; Tan, L. The impact of rising house prices on business development: literature review and path analysis. Open J. Account. 2017, 7, 73-81. [CrossRef]

10. Chaney, T.; Sraer, D.; Thesmar, D. The collateral channel: How real estate shocks affect corporate investment. Am. Econ. Rev. 2012, 102, 2381-2409. [CrossRef]

11. Chen, T.; Liu, L.X.; Zhou, L.A. The Crowding-Out Effects of Real Estate Shocks-Evidence from China; Social Science Electronic Publishing: Rochester, NY, USA, 2015.

12. Rong, Z.; Ni, J. How do housing cycles influence listed firms' R\&D investment: evidence from the collateral channel. Econ. Innov. New Technol. 2020, 29, 287-312.

13. Lu, Y.P.; Zhang, K.Z.; Ou, Y.J. Does land finance hinder regional Innovation? Based on the data of 267 prefectural-level city in China. J. Financ. Res. 2018, 5, 101-119.

14. Zheng, S.; Kahn, M.E.; Liu, H. Towards a system of open cities in China: Home prices, FDI flows and air quality in 35 major cities. Reg. Sci. Urban Econ. 2010, 40, 1-10. [CrossRef]

15. Sun, W.Z.; Zheng, S.Q.; Wu, J. Infrastructure Investment, land leasing and real estate price: a unique financing and investment channel for Urban development in Chinese cities. Econ. Res. 2014, 8, 75-81.

16. Fan, Z.J. The source of land finance: fiscal pressure or investment incentives. China Ind. Econ. 2015, 27, 18-31.

17. Deng, B.W. Effect of industrial real estate investment on innovation: evidence from listed companies in China. Res. Econ. Manag. 2014, 10, 113-120.

18. Saint-Paul, G. Fiscal Policy in an Endogenous Growth Model. Q. J. Econ. 1992, 107, 1243-1259. [CrossRef]

19. Girma, S.; Gong, Y.; Görg, H. Foreign direct investment, access to finance, and innovation activity in Chinese enterprises. World Bank Econ. Rev. 2008, 22, 367-382. [CrossRef]

20. Kong, Y.; Glascock, J.; Lu-Andrews, R. An investigation into real estate investment and economic growth in China: A dynamic panel data approach. Sustainability 2016, 8, 66. [CrossRef] 
21. Zhu, C.; Zhao, D.; Qiu, Z. Internal and external effect of estate investment upon regional innovation in China. Emerg. Mark. Financ. Trade 2019, 55, 513-530. [CrossRef]

22. Zagler, M.; Dürnecker, G. Fiscal policy and economic growth. J. Econ. Surv. 2003, 17, 397-418. [CrossRef]

23. Zhan, Y.; Li, S. Financial development, technical innovation and the construction of smart cities: An informatization development perspective. J. Financ. Econ. 2016, 42, 4-15.

24. Wang, C.; Dai, S.; Xu, H. Estimating the land opportunism of hotel investment in generating real estate appreciation and firms' market value. Land Use Policy 2018, 77, 752-759. [CrossRef]

25. Gu, Q.; Zhai, S.P. Financial constraints, R\&D investment and funding sources: The perspective of R\&D heterogeneity. Sci. Sci. Manag. S. T 2014, 35, 15-22.

26. Hall, B.H.; Moncada-Paternò-Castello, P.; Montresor, S.; Vezzani, A. Financing constraints, R\&D investments and innovative performances: New empirical evidence at the firm level for Europe. Econ. Innov. New Technol. 2016, 25, 183-196.

27. Liu, D.; Xue, J.Y.; Luo, Y.; Chen, S. Cash holdings, R\&D investment smoothing and the competition of product market: Empirical study of Chinese listed high-tech enterprises. J. Syst. Manag. 2015, 24, 717-726.

28. Zhang, J.; Yang, L.; Xin, F. Did real estate hinder the innovation in China? An analysis on loan term structure of financial system. Manag. World Chin. 2016, 5, 64-80.

29. Glaeser, E.L.; Nathanson, C.G. Housing Bubbles//Handbook of Regional and Urban Economics; Elsevier: Amsterdam, The Netherlands, 2015; Volume 5, pp. 701-751.

30. Brown, J.R.; Martinsson, G.; Petersen, B.C. Law, stock markets, and innovation. J. Financ. 2013, 68, 1517-1549. [CrossRef]

31. Bleck, A.; Liu, X. Credit expansion and credit misallocation. J. Monet. Econ. 2018, 94, 27-40. [CrossRef]

32. Wang, F.; Yao, L.Z. Does the high housing price curb the investment scale of private enterprises? J. Financ. Econ. 2018, 44, 88-100.

33. Ding, Z.; Zhang, Y.H. Taking sides in policy, low technology lock in and Chinese economy growth. China Ind. Econ. 2009, 11, 16-24.

34. Luo, Z.; Zhang, C.C. Credit expansion, real estate investment and the efficiency of resource allocation $\mathrm{n}$ in industry. J. Financ. Res. 2015, 7, 60-75.

35. Fu, D.P.; Yang, J.Y. Growing housing prices and industrial output: Promoting or restraining. Reform Econ. Syst. 2017, 5, 181-187.

36. Liu, H.; Jian, L.; Liang, J. House prices, collateral value and corporate risk-taking. J. Financ. Res. 2016, 3, 107-123.

37. Rong, Z.; Wang, W.C. Housing boom and firm's entry to real estate: evidence from listed non-real estate firms in China. J. Financ. Res. 2014, 4, 158-173.

38. Iacobucci, D. Mediation analysis and categorical variables: The final frontier. J. Consum. Psychol. 2012, 22, 582-594. [CrossRef]

39. Sobel, M.E. Asymptotic confidence intervals for indirect effects in structural equation models. Sociol. Methodol. 1982, 13, 290-312. [CrossRef]

40. Liu, X.Y. China City and Industry Innovation Report; Fudan University Industrial Development Research Center: Shanghai, China, 2017.

41. Lombardi, P.; Giordano, S.; Farouh, H.; Yousef, W. Modelling the smart city performance. Innov. Eur. J. Soc. Sci. Res. 2012, 25, 137-149. [CrossRef]

42. De Noni, I.; Orsi, L.; Belussi, F. The role of collaborative networks in supporting the innovation performances of lagging-behind European regions. Res. Policy 2018, 47, 1-13. [CrossRef]

43. Cohen, W.M. Fifty years of empirical studies of innovative activity and performance. In Handbook of the Economics of Innovation; North Holland: Oxford, UK, 2010; Volume 1, pp. 129-213.

44. Zhou, L.; Tian, L.; Gao, Y.; Ling, Y.; Fan, C.; Hou, D.; Zhou, W. How did industrial land supply respond to transitions in state strategy? An analysis of prefecture-level cities in China from 2007 to 2016. Land Use Policy 2019, 87, 104009. [CrossRef]

45. Frug, G.E.; Barron, D.J. City Bound: How States Stifle Urban Innovation; Cornell University Press: Ithaca, NY, USA, 2013.

46. Zheng, T.; Zhao, Y.; Li, J. Rising labour cost, environmental regulation and manufacturing restructuring of Chinese cities. J. Clean. Prod. 2019, 214, 583-592. [CrossRef] 
47. Yue, S.J. R\&D efficiency differences and affecting factors: A cross-province analysis using the stochastic frontier approach. Sci. Res. Manag. 2008, 29, 173-179.

48. Wang, C.H. Heterogeneous Regions, Industrial Agglomeration and Regional Innovation: A Empirical Study on Chinese Regional Panel Data. Zhejiang Soc. Sci. 2017, 11, 006.

49. Wang, C.Y.; Zhang, C. Spatial-temporal pattern of prefecture-level innovation outputs in China: An investigation using the ESDA. Sci. Geogr. Sin. 2014, 34, 1438-1444.

50. Zhou, D.M.; Ai, F.; Hu, X.W. The plundering effect of China's real estate industry on the real economy: Based on the dynamic and random simulation analysis of multiple sectors in the general equilibrium model. Contemp. Econ. Res. 2016, 11, 62-72.

(C) 2020 by the authors. Licensee MDPI, Basel, Switzerland. This article is an open access article distributed under the terms and conditions of the Creative Commons Attribution (CC BY) license (http://creativecommons.org/licenses/by/4.0/). 